\title{
Towards an Adaptive Strategic IT Governance Model for SMEs
}

\author{
Aleš Levstek ${ }^{1, *}$, Andreja Pucihar ${ }^{1}$ and Tomaž Hovelja ${ }^{2}$ \\ 1 Faculty of Organizational Sciences, University of Maribor, 4000 Kranj, Slovenia; Andreja.Pucihar@um.si \\ 2 Faculty of Computer and Information Science, University of Ljubljana, 1000 Ljubljana, Slovenia; \\ Tomaz.Hovelja@fri.uni-lj.si \\ * Correspondence: levsteka@gmail.com; Tel.: +386-(0)51699040
}

Citation: Levstek, A.; Pucihar, A. Hovelja, T. Towards an Adaptive Strategic IT Governance Model for SMEs. J. Theor. Appl. Electron. Commer. Res. 2022, 17, 230-252. https://doi.org/10.3390/ jtaer17010012

Academic Editor:

Eduardo Álvarez-Miranda

Received: 30 October 2021

Accepted: 17 January 2022

Published: 24 January 2022

Publisher's Note: MDPI stays neutral with regard to jurisdictional claims in published maps and institutional affiliations.

Copyright: (C) 2022 by the authors. Licensee MDPI, Basel, Switzerland. This article is an open access article distributed under the terms and conditions of the Creative Commons Attribution (CC BY) license (https:// creativecommons.org/licenses/by/ $4.0 /)$.

\begin{abstract}
Information technology (IT) can have a direct and indirect impact on business performance New technologies change the risks at the strategic and governing levels of an enterprise. In the age of digitalization, we need to develop new understandings and approaches to governance and management. The most established IT governance (ITG) models, such as COBIT, ITIL and CMMI, are universal, one-size-fits-all models that are not in line with contingency theory and are predominantly designed for large multinational enterprises. They are too cumbersome and cost-intensive for small and medium enterprises (SMEs) to use effectively. Therefore, there is a need to develop more efficient models that are contingency-based and easier to implement than existing models and thus adaptable to the actual needs of the business. This paper presents an empirical evaluation of key ITG mechanisms from the literature that clearly shows that several are not universally but situationally necessary, thus demonstrating the need for new contingency-based ITG models.
\end{abstract}

Keywords: IT governance; IT governance mechanisms; IT governance models; contingency IT governance model

\section{Introduction}

Rapid technological development dictates rapid changes and adjustments in enterprises at all levels, requiring new strategies and approaches to corporate governance and IT governance (ITG) [1]. In the beginning, the role of information technology (IT) was mainly to automate business processes, while today it is perceived as the main driver for the value creation of an enterprise [2]. However, without effective ITG, it can also negatively affect and reduce business value [2]. One of the critical factors for efficient and successful use of IT in enterprises is ITG [3]. Previous research has shown the positive impact of ITG on business operations. Effective governance adds value to IT projects and reduces IT and project risks [4], allowing control over IT functions [4]. Even more, an enterprise's competitive advantage and differentiation depend on effective ITG [5].

Although ITG is the subject of much discussion among researchers and practitioners, it remains a poorly understood area that is constantly changing and becoming more complex. After more than 30 years of ITG research, there are still many new themes [6]. For example, the literature often states that ITG is a part of corporate governance. Unfortunately, in practice, ITG is often the weakest part of corporate governance [2]. The main reasons for this are lack of awareness and insufficient knowledge about IT among top management, in addition to a lack of commitment to the acquisition of knowledge in this area [2,7-10].

Another problem is that previous ITG research has mainly focused on management rather than governance $[1,11]$. The boundary between management and governance is determined by governance itself and is not clearly defined. In contrast, little research has been conducted on the role of supervisory functions (supervisory board, audit committee, etc.) in ITG [2,8]. It is clear that the supervisory function has a significant impact on the efficiency of ITG and thus on business performance [2]. The supervisory role is excluded 
from the day-to-day operations of the enterprise. However, it must provide control over the management, business plans, enterprise guidance, and management support.

Enterprises have several frameworks to choose from and do not know which are the most suitable for their purpose. A growing number of ITG and related frameworks have been developed to help enterprises deal with the various components of ITG, including COBIT, PMMM, PMBOK, ITIL, CMMI, Prince2, ISO 9000, ISO 17799, Balanced Scorecard, 6 Sigma, CGEIT, Lean IT, OPBOK, BABOK, AGILE and others [12-15]. All these frameworks represent the standards, guidelines and tools that make up the ITG models.

Current ITG models are too universal, one-size-fits-all administrative nightmares [16-18] and were predominantly designed with large corporations in mind [19]. The most used frameworks to support ITG implementation in enterprises are the Information Technology Infrastructure Library (ITIL) and the Control Objectives for Information Technologies (COBIT). ITIL is a complex framework with many dependencies between processes that make it difficult to implement by enterprises. Furthermore, COBIT is too general and requires deep expert knowledge for its implementation [20,21]. However, many frameworks are similar and have much more in common than it seems at first glance. We have noticed that frameworks overlap with each other, something which hugely increases the effort of enterprises because some IT areas may need to use more than one framework to complete their tasks concisely and coherently.

Although enterprises are aware of the importance of ITG, the use of any of the wellknown ITG models is still low [22-24], especially for small and medium enterprises (SMEs) [25]. SMEs represent 99\% of all enterprises in Europe [26]. These enterprises contribute to socio-economic development by employing most of the workforce and encouraging flexibility and innovation to new market demands [27]. Given their importance, it is crucial that their IT investment also deliver the expected business value while associated risks are managed [25]. Researchers such as Bergeron and Croteau [28,29], and Devos, Landeghem and Deschoolmeester [30] emphasize that SMEs cannot be treated similarly to large enterprises. We need to consider significant differences from economic, cultural, and management perspectives [26,31].

Most ITG theories and frameworks are criticized for being intended for large enterprises rather than SMEs. This is because they do not consider the specific characteristics of SMEs that distinguish them from larger enterprises [32], especially in terms of their organizational structures, financial and IT resources and IT management structures [33]. For example, the decision-making structures of SMEs tend to be flat, informal and centralized [25]. Furthermore, time can also be an issue for these enterprises as owners and managers are regularly overloaded with other business priorities [25]. Financial and ITrelated resource limitations are much more significant in SMEs. As a result, they spend much less on IT [33] and have difficulty finding capable IT employees [34]. In addition, SME employees are more likely to be hired for their business skills to ensure core business survival and not necessarily for their technology skills. Therefore, SME employees may not be aware of the potential benefits and costs [25].

In addition, there is no clear definition in the literature of the most appropriate approach for implementing ITG in the enterprise. There are also no models based on the contingency approach. Following the contingency approach in management [35-37], we believe that a contingency approach is also needed in the field of implementing ITG. The contingency approach attempts to understand the interrelationships within and between organizational subsystems and between the organizational system as a whole and its environments. It emphasizes the multivariate nature of enterprises and attempts to interpret and understand how they operate under varying conditions [38,39].

The existing literature insists on universal ITG models that are too robust and complex for implementation in SMEs. As SMEs represent 99\% of all enterprises in the EU, create around 100 million jobs, and contribute more than half of Europe's GDP, they play a key role in adding value in every sector of the European economy [40]. As the role of IT increases in 
every enterprise to remain or to gain competitive advantage, there is a need to investigate which ITG models would be more suitable for SMEs.

Moreover, there is no clear answer to the need for a contingency approach in ITG implementation. Therefore, our study aims to investigate whether current approaches to implementing ITG mechanisms expected from current ITG models are suitable for SMEs. In this study, we focus on two research questions. The first question relates to identifying strategic level ITG mechanisms-(RQ1): What are the strategic level ITG mechanisms? The second research question relates to investigating whether the key ITG mechanisms are all universal or whether some are situational so that their importance changes during a time of implementation and use-(RQ2): Are the key ITG mechanisms all universal? To answer these questions, we first conducted an in-depth literature review and defined ITG mechanisms at a strategic level. Then, to validate the existing theory and assess the universality of the identified ITG mechanisms at the strategic level, we conducted a case study in a mediumsized enterprise in the insurance industry. As part of the case study, five interviews were conducted with managers at the strategic level of the enterprise: president of the supervisory board (SUB), president of the audit committee (ACO), top management member, responsible for IT (TOM), chief information officer (CIO) and chief business officer (CBO). The study confirmed that half of 30 identified ITG mechanisms at the strategic level can be considered situation based. Since these results are based on a single case study, they cannot be generalized. However, the results expose a serious limitation of current universal one-size-fits all ITG models, where the situational relevance of ITG mechanisms is mostly ignored. Thus, our results present a strong case for researchers to move beyond non-situational ITG models and develop new adaptive strategic ITG models based on a situational approach.

After the introduction, we present the methodology, where the literature review protocol and case study design are presented. This is followed by a detailed presentation of the case study and the results of five interviews. After this, we discuss research results and relate them to existing literature. The last part of the article presents the conclusions, limitations and recommendations for future research.

\section{Materials and Methods}

Our research is exploratory and theory testing because research in the ITG field and its contingency factors is in the early stages. Exploratory research often builds on secondary research, "such as reviewing available literature and/or data or qualitative approaches such as informal discussions with customers, employees, the management or in-depth interviews, focus projective group methods, case studies or pilot studies" [41]. The methodology for answering two research questions can be divided as follows. In the first part, which refers to the definition of ITG mechanisms at the strategic level, we used a depth literature review. The literature review results are a list of ITG mechanisms recognized in the literature as mechanisms of the strategic level. To answer the second research question referring to the suitability of current approaches in implementing universal mechanisms: Are the critical ITG mechanisms all universal? a case study with semi-structured interviews was undertaken by five members of strategic management in the medium-sized enterprise from the insurance industry.

\subsection{Literature Review}

To identify ITG mechanisms, we conducted an extensive, in-depth literature review. A review of previous, relevant literature is an essential feature of any scientific research. An effective review establishes a foundation for advanced knowledge and facilitates theory development, closes areas where substantial research exists, and uncovers areas where research is needed [42]. A literature review is defined as "the use of ideas in the literature to justify the particular approach to the topic, the selection of methods, and the demonstration that this research contributes something new" [43]. To begin a literature review, it is recommended to start with the conceptualization of the topic and a definition of key terms to derive meaningful search terms. Using these terms, we began examining journal articles 
and some of the most prominent communities, such as the OECD, ITGI, IEEE, ISACA, and publications in conference proceedings. For an initial set of databases, we used the list of journals indexed in Journal Citation Reports. We also searched the Web of Science for articles with the highest number of citations, which formed the basis for identifying relevant databases, journals, and conference proceedings. We searched for the following terms: "IT Governance", "IT Governance models", "Contingency IT Governance model", and "IT Governance mechanisms". After collecting the initial set of publications, we read the titles and abstracts of these publications and excluded those unrelated to the ITG domain. To develop a list of relevant ITG mechanisms, we selected mechanisms that were repeated in at least three articles. We limited ourselves only to mechanisms that are recognized in the literature as strategic-level mechanisms.

\subsection{Identification of Strategic ITG Mechanisms}

Governance is a concept that can be used in many contexts and is now a well-known term in business. It is focused on the role of boards of directors in representing and protecting the interests of shareholders [44,45] and addresses the proper management of enterprises [46]. While governance developments have primarily been driven by the need for the transparency of enterprise risks and the protection of shareholder value, the pervasive use of IT has created a critical dependency on IT that calls for a specific focus on ITG. Boards and executive management need to extend governance to IT and provide leadership, organizational structures and processes that ensure that the enterprise's IT sustains and extends its strategies and objectives [14].

The literature more frequently addresses enterprises governed through a one-tier corporate governance system, where one governing body (the board) performs the function of direction and supervision. In literature, this level of governance is referred to as "boardlevel" in terms of board-level ITG or board-level ITG mechanisms. However, in the two-tier system of corporate governance, which is often present in the European-continental area, supervision is separated from the corporate direction. The supervisory role is performed by the supervisory board, which supervises the board of directors entrusted with the direction. In this case, the name "board level" might lead us to misunderstand which levels are included in this denomination. To find a denomination appropriate for the one-tier and two-tier corporate governance systems, we decided to use the name "strategic level", which covers both the supervisory bodies and the direction bodies. It is generally accepted that the definition of "strategic level" in this article is the same as that of "board level", which in the literature deals with enterprises managed under a one-tier governance system.

Several authors argue that enterprises should implement ITG over IT mechanisms [47,48]. ITG can be deployed using various structures, processes and relational mechanisms [49] that encourage behaviors consistent with the organization's mission, strategy, values, norms, and culture [50]. In the literature, several authors have presented approaches to implement ITG through mechanisms, but few researchers attempt to describe and fully explain ITG mechanisms. Moreover, there is no consensus on all existing ITG mechanisms. For example, Weill and Rose [48] mention communication mechanisms, while Grembergen and De Haes [51] use rational mechanisms for the same type of ITG mechanisms. In the literature review, we highlight three of the more influential studies in the field and their attempts to identify key ITG mechanisms. The first study was conducted by Weill and Rose [48] of the Massachusetts Institute of Technology. Their research team took five years to investigate 300 enterprises in more than 20 countries and established a framework for analyzing ITG known as the CISR Pattern. Their research addressed enterprises in different industries and sought to understand how the style of governance used by strategic management affects significant IT decisions. The second approach was provided by Grembergen and De Haes [51]. Their research lists necessary ITG mechanisms by defining a minimum set of mechanisms to support ITG. Their research also addresses the difficulty of implementing an individual mechanism and the effectiveness of those mechanisms. However, their study was mostly conducted in Belgian financial services enterprises employing between 100 
and 1000 employees. Third study was conducted by Almeida, Pereira and Da Silva [52]. They analyzed more than 50 case studies to extract the ITG mechanisms used in the enterprises. We listed all relevant ITG mechanisms at the strategic level based on an extensive literature review, described them and provided the main references. We included only those mechanisms for which there are at least three references. In preparing the final list of mechanisms, we made some adjustments. For example, we decided to use the term relational mechanisms used by Grembergen and De Haes [51] instead of the term communication mechanisms used by Weill and Rose [48]. We used those names and terms that are more common in the literature. In contrast, a mechanism was classified at the strategic level if it was mentioned in the literature as a mechanism at the strategic level, regardless of the iteration number.

ITG structures enable IT to transparently provide added business value, clearly defined competencies and responsibilities while managing risks and considering business needs [53]. The structures define the roles, accountabilities, and responsibilities within the organization for all IT-related issues. They include the enterprise's organization, the role of IT, the existence of clearly defined roles, competencies and responsibilities, and various committees. When setting up the ITG, it is essential to define and formalize roles, competencies, and responsibilities. Defining roles does not only mean writing them down but performing them. All ITG stakeholders must have defined roles. One of the essential structural mechanisms is the strategic ITG committee, which operates at the strategic level of the enterprise. The committee consists of top management, B-1 managers and managers and experts responsible for decision-making in the enterprise $[48,54,55]$. The structural mechanisms derived from the literature review and defined as strategic level ITG mechanisms are shown in Table 1.

Table 1. Strategic ITG structural mechanisms.

\begin{tabular}{|c|c|c|}
\hline Structural Mechanisms & Definition & Literature \\
\hline Strategic ITG committee & $\begin{array}{l}\text { The Strategic ITG committee is situated at an executive level. } \\
\text { It is responsible for supervising and assisting management } \\
\text { in strategic issues and the strategic direction of IT. }\end{array}$ & {$[48,51,52,56-59]$.} \\
\hline Integration of governance & $\begin{array}{l}\text { Unambiguous definitions of roles, responsibilities and } \\
\text { competencies are a crucial prerequisite for an effective ITG, } \\
\text { which is the responsibility of top management. }\end{array}$ & {$[48,49,51,52,57,60]$. } \\
\hline $\begin{array}{l}\text { IT competencies at the top } \\
\text { management level }\end{array}$ & $\begin{array}{l}\text { Members of the top management must have appropriate IT } \\
\text { competencies, consisting of knowledge and experience in } \\
\text { ITG, which enables them to direct and manage IT on the } \\
\text { strategic level. }\end{array}$ & {$[48,51,52,57,61]$} \\
\hline IT investment committee & $\begin{array}{l}\text { The IT investment committee is responsible for evaluating } \\
\text { and approving significant IT investments. Other strategic } \\
\text { committees may also cover the activities of this committee. }\end{array}$ & {$[48,51,52,59,61,62]$.} \\
\hline IT organizational structure & $\begin{array}{l}\text { The possibility of effective ITG also depends on the } \\
\text { organizational structure, how the IT function is organized } \\
\text { and where the IT decision-making authority is located in } \\
\text { the organization. }\end{array}$ & {$[35,48,49,51,52,61-64]$.} \\
\hline IT audit committee & $\begin{array}{l}\text { The IT audit committee is an independent body at the level } \\
\text { of corporate governance, which is responsible for } \\
\text { identifying and managing IT risks on a strategic level. }\end{array}$ & {$[48,51,52,57,65]$} \\
\hline
\end{tabular}

ITG processes with their inputs, outputs, roles, and responsibilities determined by the definition of each process, define the ITG [66]. Processes usually evolve from structural mechanisms. By coordinating between the IT and the business, the enterprise must design the ITG processes, which are an integral part of the corporate governance [55]. When business and IT goals are aligned, it is essential to ensure successful and efficient ITG processes. Established ITG systems contain a diverse set of general IT governance and man- 
agement processes. Depending on the strategy and goals, the enterprise can develop the processes that will significantly impact IT support and business strategy. It is necessary to identify the owners of the processes and define each individual process's scope and control objectives. With the interconnection of individual processes, it is required to determine the inputs and outputs of each process, as well as competencies and responsibilities, such as a responsibility assignment matrix [67]. The process mechanisms derived from a literature review and defined as strategic level ITG processes are shown in Table 2.

Table 2. Strategic ITG process mechanisms.

\begin{tabular}{|c|c|c|}
\hline Process Mechanisms & Definition & Literature \\
\hline Financial reporting and control & $\begin{array}{l}\text { Financial reporting and control is an essential ITG process } \\
\text { related to monitoring the financial plan, reviewing costs, } \\
\text { and investments and project costs. }\end{array}$ & {$[48,50-52,57,68]$} \\
\hline $\begin{array}{l}\text { Project reporting and } \\
\text { benefits management }\end{array}$ & $\begin{array}{l}\text { Formal monitoring of IT business value improves } \\
\text { knowledge and understanding of how IT can create } \\
\text { business value. In addition, monitoring completed projects } \\
\text { determine whether the planned business goals have } \\
\text { been achieved. }\end{array}$ & {$[48,51,52,57,69]$. } \\
\hline Architectural exception process & $\begin{array}{l}\text { Technology standards are critical to IT and business } \\
\text { efficiency, though occasional exceptions are not only } \\
\text { appropriate but necessary. Enterprises use the exception } \\
\text { process to meet unique business needs and gauge when } \\
\text { existing standards are becoming obsolete. }\end{array}$ & {$[6,48,51,52,70]$.} \\
\hline ITG assurance and self-assessment & $\begin{array}{l}\text { Regular self-assessment and external verification of the ITG } \\
\text { system should be an integral part of effective ITG. }\end{array}$ & {$[52,57,59,71]$} \\
\hline Strategic information system planning & $\begin{array}{l}\text { Strategic information system planning is aligning an } \\
\text { enterprise's business strategy with an IT strategy to achieve } \\
\text { key business goals. It represents one of the essential } \\
\text { activities of strategic management. }\end{array}$ & {$[48,49,51,52,55-57,69]$.} \\
\hline
\end{tabular}

Portfolio management is an answer to the following question: "How can we maximize the business value from

IT portfolio management IT investments"? Portfolio management manages IT as a portfolio of assets similar to a financial portfolio and strives

$[51,52,57,60,62,72]$. to improve the portfolio's performance by balancing risk and return.

IT risk management must ensure the protection of IT resources, disaster recovery and business continuity. Therefore, top management must understand and identify

IT risk management IT risks and thus ensure that critical risks are under control.

IT performance measurement (e.g., IT balanced scorecard) is essential in the domains of Business Contribution, User Orientation, Operational Excellence and Future Orientation.

IT resource management is an essential process for IT that needs to be appropriately managed to achieve business performance and efficiency and ensure the proper allocation

Resource management of IT resources.

Business/IT alignment is one of the fundamental goals of ITG. Alignment is a complex concept that can be evaluated Business/IT alignment through one of the alignment models, e.g., the Strategic 
Table 2. Cont.

\begin{tabular}{|c|c|c|}
\hline Process Mechanisms & Definition & Literature \\
\hline Compliance management & $\begin{array}{l}\text { Business development and regulatory regulations are } \\
\text { increasing, especially in the financial industry. As a result, } \\
\text { compliance management (e.g., GDPR, Solvency, Basel, IDD, } \\
\text { etc.) is becoming more widespread and burdensome for } \\
\text { enterprises. Still, at the same time, it is developing } \\
\text { compliance management in enterprises. }\end{array}$ & {$[6,51,52,71,74,75]$} \\
\hline Digital transformation & $\begin{array}{l}\text { Digital management includes all those corporate } \\
\text { mechanisms that enable the coordinated operation and } \\
\text { sharing of resources throughout the enterprise. Digital } \\
\text { transformation requires a balanced top-down and } \\
\text { bottom-up approach. }\end{array}$ & {$[52,69,76,77]$} \\
\hline $\begin{array}{l}\text { Improvement and } \\
\text { innovation management }\end{array}$ & $\begin{array}{l}\text { The widespread use of IT and information systems create } \\
\text { many opportunities for innovation and improvement in } \\
\text { corporate governance. IT has become a valuable tool and } \\
\text { resource in all senses of modern business strategy. }\end{array}$ & {$[52,73,78,79]$} \\
\hline Investment management & $\begin{array}{l}\text { Determining how much money to invest in IT is crucial and } \\
\text { distributing it between maintenance, services, human } \\
\text { resources, and new projects. However, both the lack and } \\
\text { excess of IT investment can jeopardize its operations. }\end{array}$ & {$[50,52,55,60,73,80]$.} \\
\hline Outsourcing management & $\begin{array}{l}\text { Whatever the risks, outsourcing IT services is an } \\
\text { opportunity for a company to increase its capacity and } \\
\text { optimize costs. For this reason, outsourcing IT services is a } \\
\text { crucial element of ITG. }\end{array}$ & {$[52,53,71,81]$.} \\
\hline
\end{tabular}

ITG relational mechanisms represent cooperation and communication between IT and business. Appropriate communication and knowledge sharing, combined with learning and teaching, are essential $[48,54,55]$. Relationships are a crucial mechanism for ITG to achieve and maintain alignment between IT and the business, even when appropriate structures and processes are in place. The maturity of relationships in the enterprise is related to the degree to which the enterprise has managed to establish channels to ensure the flow of information and disseminate the principles of ITG. Enterprises with good relations between IT and the business have shown suitable communication mechanisms that encourage IT and the business side's cooperation. Nothing is more effective than a constructive dialogue between employees. Encouraging direct communication between IT and the business can be implemented through various mechanisms. Both horizontal and vertical communication within an enterprise is necessary to maximize efficiency. This is especially true for top management, where information sharing is crucial. The relation mechanisms derived from a literature review and defined as relationships at the strategic level of ITG are shown in Table 3.

Table 3. Strategic ITG relational mechanisms.

\begin{tabular}{lll}
\hline Relational Mechanisms & Definition & Literature \\
\hline & $\begin{array}{l}\text { This mechanism provides for the owner's active } \\
\text { involvement in the governance process. It is more } \\
\text { pronounced in the case of a one-tier corporate government } \\
\text { system, where owners mostly take on the role of } \\
\text { non-executive directors. }\end{array}$ & {$[48,52,56,60,64]$.} \\
& $\begin{array}{l}\text { The Chief Information Officer in the enterprise must present } \\
\text { the enterprise's mission, vision, and strategy in a way that } \\
\text { all IT stakeholders understand. In this context, IT leadership } \\
\text { rT leadership }\end{array}$ & $\begin{array}{l}\text { represents coordination throughout the enterprise at } \\
\text { all levels. }\end{array}$ \\
\hline
\end{tabular}


Table 3. Cont.

\begin{tabular}{|c|c|c|}
\hline Relational Mechanisms & Definition & Literature \\
\hline ITG awareness campaigns & $\begin{array}{l}\text { The campaigns aim to raise the awareness of all employees } \\
\text { in the company about ITG. Working with management staff } \\
\text { clinging to standard (current) approaches are essential to } \\
\text { understanding the ITG. }\end{array}$ & {$[48,54,57]$} \\
\hline Senior management announcements & $\begin{array}{l}\text { Notices from top management explaining an enterprise's } \\
\text { priorities usually receive considerable attention. } \\
\text { Commitment to strategic goals helps all employees to focus } \\
\text { their attention on strategic objectives. }\end{array}$ & {$[48,52,61,82]$} \\
\hline Partnership rewards and incentives & $\begin{array}{l}\text { Companies ensure that employees follow the enterprise's } \\
\text { strategy through financial rewards and employee } \\
\text { promotions that help the company achieve strategic goals. }\end{array}$ & {$[48,51,52,60,64,82]$} \\
\hline $\begin{array}{l}\text { Shared understanding of } \\
\text { business/IT objectives }\end{array}$ & $\begin{array}{l}\text { A unified understanding of business goals between IT and } \\
\text { the business side is the ability of employees to understand } \\
\text { and cooperate in achieving common goals and in respecting } \\
\text { each other's contribution and opinion. }\end{array}$ & {$[48,51,52,56,60,63,64]$.} \\
\hline $\begin{array}{l}\text { Corporate internal communication } \\
\text { addressing on a regular basis }\end{array}$ & $\begin{array}{l}\text { It is necessary to establish regular internal communication } \\
\text { about the IT activities of all employees in the enterprise. } \\
\text { Best monthly, where information on IT activities and their } \\
\text { impact on the business page is prepared. }\end{array}$ & {$[48,52,57,59,62,63]$} \\
\hline Knowledge management on ITG & $\begin{array}{l}\text { In the knowledge management of ITG knowledge in the } \\
\text { enterprise, systems for the exchange and distribution of ITG } \\
\text { knowledge are essential. }\end{array}$ & {$[48,52,57,59]$} \\
\hline $\begin{array}{l}\text { Executive/senior management give a } \\
\text { good example }\end{array}$ & $\begin{array}{l}\text { The enterprise's management, including the top } \\
\text { management, treats IT management as a partner and } \\
\text { supports standards, policies, and norms through } \\
\text { their actions. }\end{array}$ & {$[41,48,54,57]$} \\
\hline
\end{tabular}

\subsection{Case Study Design}

A case study is a method of intensive research with which we analyze and describe in detail the subject of research in time and its natural environment or space. The method is helpful for both theory testing and the development of new theories and is often used for studies in business environments [83]. The case study provides an in-depth contextual analysis of cases and relationships between them [84]. It is suitable for new research fields or cases where existing theories are inadequate or incomplete [85]. It is useful when we want the research conclusions to be descriptive rather than causal, when internal comparability is more important than external representativeness, and when we are more interested in the causal mechanisms than in the causal effects [86].

Like any other research method, the case study has its weaknesses and limitations, which we have primarily considered when carrying out the research itself. Compared with other methods, the most frequent criticism of the case study is the provision of rigor and objectivity [87-90]. To increase validity and reliability, we relied on the techniques recommended by Yin [90]. In carrying out the case study, we relied on existing and verified theories and used the concept of matching samples to evaluate the mechanisms themselves. As a disadvantage, generalization is also exposed due to restriction to one or a lesser number of research cases [84,88-91]. Our goal is not to validate a new theory but to test an existing one. If we can show that the existing theory is not valid for one case, we will be setting guidelines that are good enough for continuing our research, based on the second established theory (contingency theory), which can be used to develop an adaptive ITG model through future research.

According to the research subject, we decided to carry out a case study of an enterprise that is part of a financial insurance group in SE Europe. The interviewees, who participated in the research, come from one enterprise in the Adria region's leading insurance and 
financial group, one of the leading enterprises in south-eastern Europe. The group operates in seven markets in six countries, and through partnerships, with foreign insurance and reinsurance companies, it works in a broader international environment. The enterprise that was the subject of the survey employs 765 people, generating an annual premium of EUR 58 million. The enterprise has a history of operations dating back to 1972 and has a rich tradition. The enterprise is recognized as a leading provider of innovative and comprehensive insurance products and asset management in its environment.

For research purposes, a semi-structured interview was used, which we conducted at the different levels in the enterprise. The interviews were conducted at the strategic level of management: (1) supervisory level: the interview included the president of the supervisory board (SUB) and the president of the audit committee (ACO); (2) top management level: the interview included the top management member (TOM), who is responsible for IT. The interview also included the Chief Information Officer (CIO) and the Chief Business Officer (CBO) as representatives of business management. Basic information about the interviewees is shown in Figure 1. Interviews were conducted with all crucial supervisory board and top management members that represent key interest groups in the enterprise's strategic decision-making levels.

\begin{tabular}{|c|c|c|c|c|c|c|c|}
\hline Nr. & Age & Education & Role & Position & $\begin{array}{c}\text { Experience in } \\
\text { current } \\
\text { position }\end{array}$ & $\begin{array}{l}\text { Experience in } \\
\text { function }\end{array}$ & $\begin{array}{c}\text { Interview } \\
\text { duration } \\
\text { (hours) }\end{array}$ \\
\hline 1 & $40-50$ & Master & Supervisory board (SUB) & President of supervisory board & 10 & 20 & 1:02:03 \\
\hline 2 & $50-60$ & Bachelor & Audit committee (AUC) & President of the audit committee & 5 & 29 & $1: 52: 26$ \\
\hline 3 & $30-40$ & Master & Top management (TOM) & Top management member responsible for IT & 8 & 10 & $1: 17: 21$ \\
\hline 4 & $40-50$ & Master & Chief Information Officer (CIO) & IT Manager & 6 & 9 & $1: 02: 58$ \\
\hline 5 & $40-50$ & Bachelor & Chief business officer (CBO) & Business manager & 16 & 21 & $1: 23: 00$ \\
\hline
\end{tabular}

Figure 1. Personal information of interviewees.

The case study aims to answer the second research question (RQ2): Are the key ITG mechanisms all universal? The implementation of the research itself follows the methodology of the case study by Yin [90]. The survey protocol was adapted to the researcher's ability to conduct the survey and systematic data retrieval, which is the basis for the implementation of the interview. All five participants were presented with mechanisms stemming from the first research question and were discussed in the interview. As part of the interview, we aimed to verify whether all the ITG mechanisms were present from the very beginning of the ITG and whether they were important all the time since the ITG was implemented. We were also interested in the method and approach of the enterprise to the implementation of the mechanisms and the most established IT governance (ITG) models, such as COBIT, ITIL and CMMI.

Apart from demographic questions, the interview consisted of substantive questions: (1) Which of the presented ITG mechanisms do you consider important? Has their meaning changed over time? If yes, how? To also detect important mechanisms from some time ago, we also asked the question: (2) Have other mechanisms been important in the past? Which ones? Why are they no longer important? To assist with the study protocol, a database in MS Excel format was created containing all the essential elements, code lists and instructions for conducting interviews and storing and recording notes during the interview. In addition to the data collected by the interviews, the database also contains summaries and transcripts of individual statements, sent documentation, a video or audio recording of the interview, a signed statement by the interviewee to participate in the research and data processing, and other collected documentation about the case in question. We prepared an e-mail template for the interview invitation, which was sent to all interviewees. In addition to the content of the e-mail, which briefly described the purpose and objectives of the interview and the course of the interview, the e-mail contained the following attachments: descriptions of the mechanisms that were the subject of the interviews and an accession statement for 
participation in the research and permission for data processing using a questionnaire. Before drafting the final questionnaire, we conducted a pilot interview with one of the interviewees, which was the basis for adapting the questionnaire approach and the order of the questions. A total of 5 interviews were conducted. On average, the interview lasted $1.2 \mathrm{~h}$. The number of interviews conducted to make qualitative research credible varies from one author to another. All authors point out that the only objective criterion is data saturation, where data are repeated and do not contribute to new knowledge [92-94], which was also considered in the interviews.

The evaluation of the mechanisms was carried out in such a way that we recorded the opinion of our interviewees on the questions raised about the mechanisms, their importance, the dependence of importance on time and other factors, their interconnection and their meaning. We then analyzed the frequencies (repeated answers) for the mechanisms they consider permanently important or situationally important. The mechanisms that the interviewees have identified as being permanently substantial have been described as universal mechanisms. The mechanisms, which in most cases are considered to be of particular situational or recurrent importance, have been described as situational mechanisms. The basis of the analysis is the number of sample matching repetitions on which the importance of each mechanism as universal or situational can be determined. Our study is exploratory and based on a case study where we used interviews. In the interviews, we followed the case study methodology proposed by Yin [90]. We systematically asked all interviewees about each ITG mechanism from three different perspectives: which mechanisms were significant at the beginning, which are essential now, and how has the importance changed over time? If the statement for a particular mechanism is repeated in four (4) out of five (5) roles of the interviewees included in the survey, the result was accepted as a satisfactory validation of the importance of the mechanism.

\section{Results}

The results of the research can be roughly divided into two parts. The first part of the results refers to the literature review and the first research question, which requires the definition of ITG mechanisms at the strategic level. The result of the in-depth literature review is a list of ITG mechanisms, which are recognized in the literature as ITG mechanisms of the strategic level and are the basis for performing qualitative research. The second part of the results comes from qualitative research and is based on the case study or interviews.

\subsection{Case Study}

In the case study analysis, we limited ourselves to the mechanisms that the interviewees considered to be situation specific. Their importance depends on the specific situation and is not consistently present within the ITG. The following is a summary of the situational mechanisms as seen by the interviewees.

The president of the supervisory board $(S U B)$ is also the executive director of the group management area of the parent enterprise. He performs supervisory functions in several enterprises and has many years of experience in corporate governance. He is an economist by education and started his career in the financial industry in sales. He is very familiar with the enterprise's operations and is aware of the importance of IT, which has a significant influence on the enterprise's strategy. As for structural mechanisms, he pointed to three situational mechanisms: integration of governance, IT competencies at the top management level and IT organizational structures. The integration of governance is essential when it is necessary to define the responsibilities and accountabilities for IT issues in the enterprise. He believes that to establish an efficient ITG at the enterprise, the top management needs a certain level of knowledge about ITG. If these competencies are not at a sufficient level, there will also be no adequate support. He sees IT organizational structures as important when ITG building starts, but not otherwise. The integration of governance and IT organizational structures are thus important at the beginning of ITG building and depend directly on the compatibility of the mechanisms with the existing structures. He highlighted the 
process mechanisms as situational: financial reporting and control, strategic information system planning, digital transformation, and project reporting and benefits management. He sees strategic information system planning as a mechanism that is important periodically and as such depends on the enterprise's strategic planning cycle or enterprise strategy and its maturity. He sees digital transformation as an external situational mechanism. The financial industry introduces novelties when they are verified on the market, and the appropriate legislative and regulatory bases must be in place to do so. He sees project reporting and benefits management and financial reporting and control as control mechanisms that only become noticeable in mature periods when we want to raise the maturity of management. He does not see any sense in implementing control mechanisms if there are no management bases in place that allow this. In relational mechanisms, he considers the following mechanism situational: knowledge management on ITG, which is important in the enterprise from two aspects. Firstly, at the beginning of ITG building (establishment) and in situations where knowledge about ITG is at a low level, the enterprise needs to acquire basic knowledge about ITG and its placement, and then secondly when it is necessary to raise the maturity of the ITG. Related to the question about implementing best practices, models, and standards such as COBIT, ITIL and CMMI, he answered that they are certainly an important tool, but cautioned to not use them as a cooking recipe and using their ITG mechanisms without a deep understanding for what reasons they should be applied. He described a bad experience he had in the past when the company blindly followed the implementation of a project management model without the appropriate knowledge and expertise.

The president of the audit committee $(A C O)$ is a former member of the executive board who has a lot of experience in supervision and top management since he has held this function in several enterprises. He had previously encountered the area of ITG as the president of the management board, but today he is looking at this area from the viewpoint of the audit committee management. In the past, as a representative of top management, he was actively involved in the design of ITG mechanisms, which are intended for development management, so that he has rich experience in this field. In the case of structural mechanisms, he defined as situational the following mechanisms: integration of governance, IT competencies at the top management level, IT organizational structure and IT audit committee. Integration of governance is important when the enterprise does not know who is competent and responsible for IT issues, or what is necessary. IT organizational structure is important when needed to position IT at the same level as other business functions. At the beginning of the establishment of the ITG and later, to increase the level of maturity and implement new mechanisms, management support and a certain level of knowledge are required, which he sees in the role of the IT competencies at the top management level mechanism. In the case of the IT audit committee, he believes that, in a situation where the committee has to deal with IT issues, it needs at least one member who understands IT and can explain it to the other members. In process mechanisms, he defined as situational the following: financial reporting and control, project reporting and benefits management, IT performance management, digital transformation, investment management and outsourcing management. He thinks that financial reporting and control are feasible and essential when the financial service and other business areas support this, requiring a specific enterprise processes maturity. Project reporting and benefits management does not make sense if the enterprise does not have appropriate structures, such as project management at a proper level of maturity. In later periods, especially considering the rising maturity of the ITG, IT performance management is noticeable when the enterprise wants to closely monitor specific performance indicators, which are primarily intended to raise service maturity. Digital transformation is an essential mechanism in certain situations where the enterprise follows market changes, which must be supported by regulations in the financial industry. Regarding investment management, he thinks that the importance of this mechanism arises in a situation where an enterprise fails to provide sufficient resources for development or needs to be managed more efficiently. He thinks that the outsourcing management mechanism is essential when an enterprise decides to outsource a particular service. Some conditions regarding service quality and economic 
effects must be met. Finally, he points out knowledge management on ITG in the context of the relational mechanisms as a mechanism that occurs in certain situations. He agrees that knowledge must be managed appropriately, especially in specific situations at the beginning of deployment and raising maturity. In the absence of the necessary knowledge on ITG, especially in the case of high complexity and low maturity, it will be challenging to identify the required benefits of ITG implementation, which is crucial to the success of ITG implementation. He is non-committal in connection with the question about implementing best practices, models, and standards such as COBIT, ITIL and CMMI models. He believes that the company must first understand what issues it wants to solve and only then start with the implementation of standard models. he presented an unsuccessful example of implementing a data model into a data warehouse. He states if a company cannot calculate what it wants in Excel, models cannot help it either.

The top management member (TOM), who oversees IT in the enterprise, is one of the group's younger representatives of top management with several years of experience in similar jobs. He is a representative of the younger generation of top management, who has a great understanding of the support and role of IT in the enterprise, which is also reflected in the success of the enterprise itself, the role of IT in the enterprise and the business-IT alignment. Within the framework of the structural mechanisms, he defined the integration of governance and IT organizational structure as distinctly situational. He believes that if the enterprise does not know who is responsible for what, this should be done immediately at the beginning of the ITG implementation. This also applies to the IT organizational structure. Suppose IT is not organizationally positioned at the same level as the other business areas, which depends to a large extent on the strategy of the enterprise, in that case one cannot expect harmonized business operations and IT governance. In the field of process mechanisms, he defines the following as situational: financial reporting and control, strategic information system planning, digital transformation, and outsourcing management. If financial planning and control are to be carried out at a more in-depth level, such as activity-based costing, this must be followed by the whole enterprise. Otherwise, it does not make any sense. He sees strategic information system planning as a steering mechanism through which business areas are coordinated. Once a year, the enterprise checks strategic orientations, which are then passed to operational levels, where communication or information flow plays a key role. He believes that digital transformation has a significant impact on the long-term strategy of the enterprise, but to be effective, several factors need to be met. The internal maturity of processes and the enterprise is essential, as well as the market and regulations. He sees the outsourcing management mechanism in IT as an opportunity to shift existing resources from "technology" to "business". This mechanism also requires a certain maturity and an appropriate staff rejuvenation. This is particularly true in the IT sector and is closely linked to the enterprise's strategy. In the context of the relational mechanisms, he has not highlighted any mechanism as being particularly situation specific. To the question of implementing best practices, models, and standards such as the COBIT, ITIL and CMMI models, he believes that, for SMEs, these are most suitable in a form tailored to their actual needs and capabilities. The latter is also evident in the current implementation of mechanisms that each enterprise in the group has implemented according to their needs and abilities.

The Chief Information Officer (CIO) is one of the group's most successful and valued IT managers. In this role, he has also worked in other enterprises operating on international markets, so he has rich experience at the ITG level in related enterprises. He represents the younger generation of IT managers, who are more focused on business informatics and less on information technology. He understands the ITG as connecting business parts and IT, which he considers necessary. Within the framework of the structural mechanisms, he pointed out the integration of governance and the IT audit committee as situation specific. The integration of governance is initially necessary if the enterprise does not know who is responsible for making decisions relating to IT, primarily from a business perspective. In the event of difficulties in addressing audit recommendations, it is necessary to provide 
separate thematic meetings of the audit committee for IT purposes. In the context of process mechanisms, he defines as situational the following mechanisms: project reporting and benefits management, strategic information system planning, digital transformation, and outsourcing management. He believes project reporting and benefits management is essential when the enterprise wants to raise the maturity of the ITG to a higher level. Appropriate structures, such as the project office, maturity of other processes, and adequate financial reporting and supervision are prerequisites. He sees the strategic information system planning mechanism as a direction that focuses on strategic projects, which helps IT make priorities. The mechanism is periodically noticeable in the framework of the annual planning and updating of the enterprise strategy in a situation where the views of the business parts are different from the IT view. The digital transformation mechanism is important in a situation where an enterprise is opting for digitization, which can be internally or externally motivated. This requires certain conditions to be met, such as processes maturity, availability of resources, financial aspect, and appropriate regulation. He sees the outsourcing management mechanism as important and useful, especially in situations where the enterprise wants to shift its IT resources to business areas rather than technology. This requires certain conditions to be met, such as cost, maturity of processes and services in the enterprise, and regulation. The outsourced services must be provided to the enterprise with the same or better availability at a lower price. Within the framework of relational mechanisms, he defines knowledge management on ITG as a situational mechanism. He sees the importance of this mechanism primarily at the beginning of ITG implementation when all stakeholders in the enterprise need to have reached a certain common level of understanding if the ITG implementation is to be successful. Of the most popular COBIT, ITIL and CMMI models, in his opinion the enterprise has the most experience in implementing ITIL. Implementing processes in the enterprise takes place gradually, tailored and as needed. The greatest limits are the available knowledge and the required resources. The implementation of processes should, in his opinion, begin with the emergence of actual needs or an audit recommendation, where he highlights as an example the implementation of an incident management process.

The Chief Business Officer ( $C B O$ ) has many years of experience in business management and is responsible for business development in the enterprise. In this role, he has also worked in an international environment. He is an experienced manager who has an extensive overview of the events in his immediate and more comprehensive surroundings, both in business and personally. He monitors the global micro and macro-economic picture and operates at the country's level in forums and associations that have a significant impact on the development of the financial sector in the country. Within the framework of the structural mechanisms, he pointed out the integration of governance, the IT organizational structure and the IT audit committee as situation specific. For an efficient ITG, IT must be appropriately placed in the organizational structure of the enterprise. Responsibilities and accountabilities at all levels of the enterprise also need to be adequately defined. Both mechanisms are therefore required at the beginning of ITG establishment and in situations where it is necessary to regulate the role and responsibilities of IT in the enterprise. If IT audit recommendations are continuously extended within the audit committee and pose risks to the enterprise's business, separate IT-related discussions should be provided. In the context of process mechanisms, he defines as situational the following mechanisms: financial reporting and control, project reporting and benefits management, strategic information system planning, digital transformation and outsourcing management. Financial reporting and control are carried out in all enterprises according to accounting standards, and from the IT point of view gives a macro perspective. Suppose an enterprise wishes to raise maturity in later periods of the ITG, in that case it may establish a more in-depth level of financial reporting, which the whole enterprise must follow. Similarly, project reporting and benefits management only makes sense when the enterprise has the necessary structures and processes to support project management. He agrees that strategic information system planning is an important mechanism but emphasizes that implementation is more important from his point of view. He says itis important for the enterprise to set up a "compass" 
but even more critical to reach the goal. As the planning cycle happens once a year, this mechanism is considered important at certain times and in a situation where the enterprise sees that it is not achieving its strategic objectives. He believes that digital transformation is undoubtedly a process whose importance will grow. Enterprises must monitor the progress of digitization in their surroundings, follow trends and build the necessary skills for transformation once the conditions are created. A little part of the business is currently going through digital channels, but they are preparing for when the conditions are created to raise the importance of this mechanism. In outsourcing management, he sees a strictly regulated mechanism that applies especially to enterprises in the financial industry. For enterprises to start outsourcing services that support their core activities, the suppliers, the market, and the regulation must evolve accordingly. Regarding the relational mechanisms, he defines knowledge management on ITG as a situational mechanism. The management and business parts must be aware of the limitations arising from IT. It is important to be aware that it is not possible to get everything immediately. In these situations, knowledge, competencies, and an appropriate flow of information are of crucial importance. When asked about his opinion on the implementation of best practices, models, and standards such as the COBIT, ITIL and CMMI models, he emphasized the benefits of being familiar with such models. However, in his opinion, their implementation must be situational, which requires a certain maturity from the company. As he says, financial reporting on projects is irrelevant if the company does not effectively manage project management. Large generic models are in his opinion not suitable for SME companies.

\subsection{Universal and Situational ITG Mechanisms}

Figure 2 shows the replication of the interviewees' opinions on the importance of the mechanisms, expressed as situational or universal. In the first part of the table, we have marked the mechanisms that interviewees believe in most cases to be situationspecific and have described them as situational mechanisms. The second part of the table contains mechanisms that interviewees consider to be of universal importance or that their importance is continuously present within the ITG. We have described these mechanisms as universal mechanisms. If the assessment of the importance of each mechanism is repeated in four (4) out of five (5) roles, this is considered to be a satisfactory validation of the mechanism evaluation. According to the results of the qualitative analysis, the interviewees described half of the mechanisms as situational and the other half as universal.

From a research perspective, we focused on situational mechanisms that interviewees identified as important at different time periods of the ITG and whose importance depends on certain situations. Based on a qualitative analysis, half of the considered mechanisms can be defined as situational mechanisms. Of these, we can confirm situational importance for eight of them, as it is repeated in four out of five roles. In all five roles, the integration of governance and digital transformation mechanisms are repeated. In four out of five roles, the following mechanisms are repeated: IT organizational structure, financial reporting and control, project reporting and benefits management, outsourcing management and Knowledge management on ITG. The importance of these mechanisms can be broadly classified into four groups: (1) mechanisms that are important at the beginning of ITG implementation; (2) mechanisms that are important after ITG implementation to raise maturity; (3) mechanisms whose importance depends on external factors; and (4) mechanisms whose importance depends on other mechanisms and is performed periodically or occasionally, such as annual planning. The interviewees have identified the following mechanisms as needed the beginning of ITG in the enterprise: integration of governance and IT organizational structure. Defining responsibilities and accountabilities by placing IT properly in the organizational structure of the enterprise is a prerequisite for ITG to be developed in the enterprise. They believe that it is impossible to talk about the ITG if the enterprise does not know who is competent and responsible for the information-technology or information-business part. The integration of governance is closely linked to the IT organizational structure. They believe that it is impossible to achieve harmonization, which is the fundamental task of the ITG if the IT 
part is not an equal partner to the business part. When the powers, responsibilities and organizational aspects are clearly defined at the beginning of ITG implementation, the importance of both mechanisms is no longer at the forefront. In the later period of the ITG, both mechanisms are no longer as important as they are at the beginning. Compatibility with the enterprise's existing structures and strategy, which defines IT's role, has an impact on both mechanisms. This group can also include knowledge management on ITG, which helps to establish a unified view of ITG and raise the necessary competencies, both of which undoubtedly contribute to the success of ITG implementation in the enterprise. The latter is also important during the period of raising the maturity of the ITG, where the interviewees also include financial reporting and control and project reporting and benefits management. The interviewees consider that the importance of both mechanisms is noticeable at a time when the ITG is being structured, and there are discussions about the raising of ITG maturity. The implementation of these mechanisms has no effect until the conditions are created. For example, if there is no project management in the enterprise, it is difficult to talk about project control. Both mechanisms are thus directly influenced by the organizational structure and maturity of the enterprise, which is expressed through the maturity of the individual processes. Among the mechanisms for which interviewees believe their importance depends on external factors, they have identified digital transformation and outsourcing management. For both mechanisms, certain conditions must be established so that their implementation is reasonable. digital transformation in this part is understood as a mechanism that influences the transformation of the business. The financial industry is conservative and introduces innovations when they are verified on the market. The digitalization of the business is also subject to appropriate regulation, which often lags when compared to technological developments, thus posing a major obstacle to digitalization. Outsourcing primary business services are also subject to a conservative approach, and interviewees say that at least two conditions have to be met. Service availability and price must be appropriate, where shorter development cycles are expected than the current ones.

Interviewees indicated that half of the universal mechanisms considered were of constant importance throughout the various ITG periods. Of these, we can confirm the universal importance for eight of them, as the importance was repeated in four out of five roles. In all five roles the following mechanisms are repeated: strategic ITG committee, IT risk management, resource management, business/IT alignment, partnerships rewards and incentives, shared understanding of business/IT objectives and executive/senior management give the good example. In four out of five roles, only one mechanism is repeated, IT leadership. The Strategic ITG committee was identified by interviewees as an umbrella mechanism which forms the basis of the ITG and guides the development and implementation of the ITG in the enterprise. They agree that in the case of process mechanisms, the mission of ITG is expressed through the mechanism business/IT alignment, which must be permanently present in the ITG. This includes IT risk management and resource management. The interviews have repeatedly pointed out that there is no business process that does not depend on IT, so when we talk about IT risks, we are talking about business risks, which is sufficient reason to manage them. The opinions of the interviewees were also unified when referring to resources. At present, resources present a significant challenge, especially in the field of IT. Resources are always lower than business needs and therefore need to be managed efficiently. In terms of relational mechanisms, all interviewees agreed that they form the basis for building on informal relations, enabling formal structures and processes to function. They pointed out the IT Leadership mechanism, which allows IT to be raised to the equivalent level of other business areas. The common view is that any good work done deserves a reward, which is the role of the partnership rewards and incentives mechanism. A shared understanding of business/IT objectives is seen as a mechanism that enables the process of harmonization between IT and business. As was repeatedly exposed in the interviews, the most challenging issues are solved by informal communication. Last but not least, executive/senior management give good example is indispensable in medium-sized enterprise environments. Regarding the direct question about the implementation of best practices, 
models, and standards such as the COBIT, ITIL and CMMI models, all interviewees were reserved. Their opinion is that there are not enough resources to spend on the stock. Therefore, the implementation of mechanisms depends on the situation according to the actual needs and the enterprise's capabilities.

\begin{tabular}{|c|c|c|c|c|c|c|c|c|}
\hline Nr. & & STRATEGIC ITG MECHANISMS & SUB & $\mathrm{ACO}$ & TOM & $\mathrm{CIO}$ & $\mathrm{CBO}$ & RITGM \\
\hline 1 & \multirow{15}{*}{ 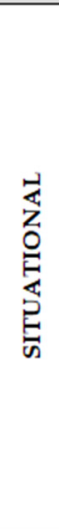 } & Integration of governance & $\checkmark$ & $\checkmark$ & $\checkmark$ & $\checkmark$ & $\checkmark$ & $\checkmark$ \\
\hline 2 & & IT competencies at the top management level & $\checkmark$ & $\checkmark$ & & & & \\
\hline 3 & & IT investment committee & & & $\checkmark$ & & $\checkmark$ & \\
\hline 4 & & IT organizational structure & $\sqrt{ }$ & $\checkmark$ & $\checkmark$ & & $\sqrt{ }$ & $\checkmark$ \\
\hline 5 & & IT audit committee & & $\checkmark$ & & $\checkmark$ & $\sqrt{ }$ & \\
\hline 6 & & Financial reporting and control & $\sqrt{ }$ & $\checkmark$ & $\checkmark$ & & $\sqrt{ }$ & $\checkmark$ \\
\hline 7 & & Project reporting and benefits management & $\sqrt{ }$ & $\sqrt{ }$ & & $\sqrt{ }$ & $\sqrt{ }$ & $\sqrt{ }$ \\
\hline 8 & & Architectural exception process & & & $\checkmark$ & & & \\
\hline 9 & & ITG assurance and self assessment & & $\sqrt{ }$ & & & & \\
\hline 10 & & Strategic information system planning & $\checkmark$ & & $\checkmark$ & $\checkmark$ & $\checkmark$ & $\checkmark$ \\
\hline 11 & & IT performance measturement & & & & & & \\
\hline 12 & & Digital transformation & $\sqrt{ }$ & $\checkmark$ & $\checkmark$ & $\sqrt{ }$ & $\sqrt{ }$ & $\sqrt{ }$ \\
\hline 13 & & Investment management & & $\sqrt{ }$ & & & $\sqrt{ }$ & \\
\hline 14 & & Outsourcing management & & $\checkmark$ & $\checkmark$ & $\sqrt{ }$ & $\sqrt{ }$ & $\sqrt{ }$ \\
\hline 15 & & Knowledge management on ITG & $\checkmark$ & $\sqrt{ }$ & & $\sqrt{ }$ & $\checkmark$ & $\sqrt{ }$ \\
\hline 16 & \multirow{15}{*}{ 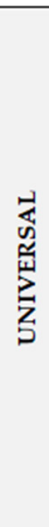 } & Strategic ITG committee & $\checkmark$ & $\sqrt{ }$ & $\checkmark$ & $\sqrt{ }$ & $\sqrt{ }$ & $\checkmark$ \\
\hline 17 & & IT portfolio management & & $\sqrt{ }$ & & $\sqrt{ }$ & $\sqrt{ }$ & \\
\hline 18 & & IT risk management & $\sqrt{ }$ & $\checkmark$ & $\checkmark$ & $\sqrt{ }$ & $\sqrt{ }$ & $\sqrt{ }$ \\
\hline 19 & & Resource management & $\sqrt{ }$ & $\checkmark$ & $\checkmark$ & $\sqrt{ }$ & $\sqrt{ }$ & $\checkmark$ \\
\hline 20 & & Business/IT alignment & $\sqrt{ }$ & $\checkmark$ & $\checkmark$ & $\sqrt{ }$ & $\sqrt{ }$ & $\checkmark$ \\
\hline 21 & & Compliance management & & $\sqrt{ }$ & & & $\sqrt{ }$ & \\
\hline 22 & & Improvement and innovation management & & & & $\checkmark$ & $\checkmark$ & \\
\hline 23 & & Active principal participation & & & & & & \\
\hline 24 & & IT leadership & $\sqrt{ }$ & $\checkmark$ & & $\sqrt{ }$ & $\checkmark$ & $\sqrt{ }$ \\
\hline 25 & & ITG awareness campaigns & & & & & $\checkmark$ & \\
\hline 26 & & Senior management announcements & & $\checkmark$ & & & & \\
\hline 27 & & Partnership rewards and incentives & $\sqrt{ }$ & $\sqrt{ }$ & $\checkmark$ & $\sqrt{ }$ & $\sqrt{ }$ & $\checkmark$ \\
\hline 28 & & Shared understanding of business/IT objectives & $\checkmark$ & $\checkmark$ & $\checkmark$ & $\sqrt{ }$ & $\checkmark$ & $\checkmark$ \\
\hline 29 & & Corporate internal communication addressing on a regular basis & & & & & $\checkmark$ & \\
\hline 30 & & Executive/senior management give the good example & $\sqrt{ }$ & $\sqrt{ }$ & $\sqrt{ }$ & $\checkmark$ & $\checkmark$ & $\sqrt{ }$ \\
\hline
\end{tabular}

Legend:

SUB President of the supervisory board

ACO President of the audit committee

TOM Top management member responsible for IT

CIO Chief Information Officer

CBO Chief Business Officer

RITGM Replicated ITG mechanisms

Figure 2. Situational and universal ITG mechanisms.

\section{Discussion}

There is no clear definition in the literature of the most appropriate approach for implementing ITG mechanisms in SMEs. The adoption of all well-known ITG models are still low [22-24], especially in SMEs [25]. Major well-known models are also not based on the contingency approach. Therefore, the aim of our study was to investigate whether the current ITG models are suitable for SMEs. We also aimed to verify whether there is a clear need for the development of ITG models based on a situational approach. Since these results are based on a single case study, they cannot be generalized. However, the results of our study provide an important foundation for future research as they confirm the need to develop an adaptive strategic ITG model based on a situational approach.

With the literature review, we have defined the key mechanisms of the ITG at the strategic level, and with the case study, we have examined whether all mechanisms are universal and important in all situations. Based on response replication, the interviewees defined half of the mechanisms as mechanisms whose implementation and importance 
depend on a particular situation. The implementation of certain mechanisms is necessary at the very beginning of ITG implementation (such as integration of governance and IT organizational structure), and later their importance decreases. Certain mechanisms are important in a situation where an enterprise wants to raise the maturity of the ITG (such as financial reporting and control and project reporting and benefits management) and are not relevant at the very beginning of ITG implementation. Some mechanisms (such as digital transformation and outsourcing management) have proven to be important in situations influenced by external factors such as competition, the arrival of new technologies, regulation, etc. In some cases, the interviewees connected the importance of the mechanisms with internal factors or other mechanisms and processes in the enterprise, which can be performed either permanently or periodically (such as strategic information system planning). Based on the replication of responses repeated in four out of five roles, we can confirm with great certainty that the implementation of eight out of thirty mechanisms is situation based and requires a situation-based approach.

The research results of our study provide an important theoretical contribution. Based on response replication, we can conclude that the implementation of ITG mechanisms is not universal but the appropriate ITG mechanisms for implementation need to be selected on a situational basis. The current ITG models, which expect a universal approach to implementation of ITG mechanisms, are unsuitable for SMEs and other enterprises with limited resources. All interviewees echoed such a position through their views on implementation of best practices, models, and standards such as the COBIT, ITIL and CMMI models. The presented interviews show a clear need for new ITG models which are based on contingency theory. Our study showed that certain specific mechanisms are clearly situational, and their importance is expressed by the impact or occurrence of certain contingency factors, or their importance occurs periodically. The theoretical contribution of the research underlines the need for further research towards the development of an adaptive model of strategic ITG based on contingency theory.

The practical contribution of the research is intended for corporate management as a guide for the implementation of ITG mechanisms. Literature often states that each implementation of ITG in an enterprise is a particular example and that if something works in one enterprise, it does not necessarily work in another. However, it does not answer how the implementation of the mechanisms should be carried out to ensure success. The direction of the practical contribution of the research is that top management should not blindly follow the extensive and comprehensive ITG models. Still, it should critically and situationally assess which of the mechanisms they need at a given moment. With the contingency approach, they increase the efficiency and effectiveness of implementation and respond directly to the enterprise's needs for ITG at a given moment.

The literature review has revealed different approaches to the implementation of ITG mechanisms. With the publication of his research in 2004 [48], Weill laid the foundations for modern ITG. In a study that lasted five years, he researched ITG in more than 300 companies and presented various ITG patterns. The research was designed to understand how various areas of ITG are managed (in this case, IT principles, IT architecture, IT infrastructure, business applications needs and IT investment and prioritization). The research shows different management styles (from a more decentralized to a more centralized style), which helps top management identify what IT decisions need to be adopted in the enterprise and who needs to adopt them. Another approach is observed in the studies of Van Grembergen and de Haes [95], which define different approaches and strategies for implementing ITG into enterprises. A comprehensive survey of Belgian enterprises in the financial industry presented the "minimum baseline of ITG practices" that enterprises should implement. There are also several academic frameworks in the literature. Selig [12] presented an academic framework based on available standards, frameworks and best practices in which he sets guidelines and best practices for implementation into the enterprise. Dahlberg and Lahdelma [53] presented the ITG model, whose implementation is based on different levels of maturity of ITG. Almeida, Pereira and Da Silva [96,97] highlighted the contingency 
factors that impact ITG. Other authors $[2,13,98,99]$ also discuss the impact of contingency factors on ITG. However, these cases are mostly limited to the influence of one factor or the overall influence on ITG. Researchers, such as Bartenschlager and Goeken [100], explored the impact of business/IT alignment on ITG and proposed models for alignment. Luftman [63] proposed a model for strategic alignment, which he sees as the basic mission of ITG. Van Grembergen [51] also addressed the implementation of ITG from various aspects, from strategic approaches to a minimum set of mechanisms. In cooperation with Rowlands and de Haes [101], they discussed the impact of organizational culture and the competencies of top management on the success of ITG implementation. Most of the time, these studies focus on the impact of an individual contingency factor and do not address the impact of all factors on all ITG mechanisms. However, these studies have a common discovery that each implementation is specific and that certain approaches that work in one enterprise do not necessarily work in another [64]. Different enterprises need different mechanisms and approaches to the implementation of ITG mechanisms [67]. Various studies focusing on the range of mechanisms enterprises need as a "minimal baseline of ITG mechanisms" have highlighted different mechanisms, these include Van Grembergen and de Haes [41], Pereira [102], and Almeida and da Silva [97] who all show that the minimum set of mechanisms varies between different enterprises, something which indirectly supports our discovery of the importance of a situational approach. In our study, we divided ITG mechanisms into mechanisms that are distinctly situational, and universal mechanisms, which means that they are present in almost all situations. Certain mechanisms that we have identified as universal (such as strategic ITG committee, IT risk management, resource management, etc.) correspond to mechanisms that other authors define as minimum necessary mechanisms. The proposed concept of a contingency approach thus builds on existing models and fills a gap that provides an answer as to why each ITG implementation in enterprises is different and why enterprises need different mechanisms.

\section{Conclusions}

There is no single approach to implementing ITG mechanisms that would meet an individual enterprise's specific situations [49]. ITG implementation is influenced by external and internal contingency factors [103]. Nevertheless, the literature fails to clearly identify these factors and their impact on ITG models and ITG implementation [104]. Most frameworks state that there is no single best IT organizational structure or governance arrangement because IT needs to respond to the unique environments within which it exists [6,105], but does not specify the factors that can influence each ITG implementation [52]. Existing ITG models are primarily intended for large enterprises and, as such, are not suitable for SMEs. Considering their relevance, it is crucial that their IT investment also deliver the expected business value while associated risks are managed [25]. Moreover, some of the most used and well-known frameworks are complex, too general, lacking a theoretical foundation from a scientific viewpoint [102] and overlapping, which was also confirmed by our research.

As there are no clear guidelines in the existing literature, our research was intended to examine the importance of a contingency approach in implementing ITG mechanisms and whether there is a clear need to develop a new model based on the contingency approach. In our article, we answered two research questions. In the first part of the article, based on the literature review, we answered the first research question (RQ1): What are the strategic level ITG mechanisms? The answer to RQ1 is a list of ITG mechanisms recognized in the literature as ITG mechanisms at the strategic level. In selecting mechanisms, we have limited ourselves to mechanisms that appear in the literature review in at least three articles. The list of ITG mechanisms at the strategic level provides the basis for a case study that answers the second research question (RQ2): Are the key ITG mechanisms all universal? In our research, we were interested to know whether all mechanisms were important in all situations and whether there was a clear need for new ITG models based on contingency theory. Based on the replication of interviewees' answers, it can be concluded 
that in the enterprise under consideration, some mechanisms are clearly situation based, and some are universal. The exploratory ITG model, which shows all the mechanisms that the interviewees predominantly see as situational or universal are shown in Figure 3. With these findings, we question the existing theory of exclusively universal ITG models and set guidelines for further development of an adaptive strategic ITG model based on contingency theory.

\begin{tabular}{|c|c|c|}
\hline \multicolumn{3}{|c|}{ IT Governance model } \\
\hline Structural mechanisms & Process mechanisms & Relational mechanisms \\
\hline Universal structural mechanisms & Universal process mechanisms & Universal relational mechanisms \\
\hline Strategic ITG committee & $\begin{array}{l}\text { IT portfolio management } \\
\text { IT risk management } \\
\text { Resource management } \\
\text { Business/IT alignment } \\
\text { Compliance management } \\
\text { Improvement and innovation management }\end{array}$ & $\begin{array}{l}\text { Active principal participation } \\
\text { IT leadership } \\
\text { ITG awareness campaigns } \\
\text { Senior management announcements } \\
\text { Partnership rewards and incentives } \\
\text { Shared understanding of business/IT objectives } \\
\text { Corporate internal communication addressing } \\
\text { on a regular basis } \\
\text { Executive/senior management give the good } \\
\text { example }\end{array}$ \\
\hline Situational structural mechanisms & Situational process mechanisms & Situational relational mechanisms \\
\hline $\begin{array}{l}\text { Integration of governance } \\
\text { IT competencies at the top management level } \\
\text { IT investment committee } \\
\text { IT organizational structure } \\
\text { IT audit committee }\end{array}$ & $\begin{array}{l}\text { Financial reporting and control } \\
\text { Project reporting and benefits management } \\
\text { Architectural exception process } \\
\text { ITG assurance and self assessment } \\
\text { Strategic information system planning } \\
\text { IT performance measurement } \\
\text { Digital transformation } \\
\text { Investment management } \\
\text { Outsourcing management }\end{array}$ & Knowledge management on ITG \\
\hline
\end{tabular}

Figure 3. Exploratory ITG model with situational and universal ITG mechanisms.

Our study also has limitations, which highlight opportunities for further research. Because research in the field of ITG and its contingency factors is in the early stages, our research is exploratory and theory testing. The purpose of our research was to test the existing theory. Therefore, in this step of our research journey, we limited ourselves to a single case study. Further research towards an adaptive strategic ITG model for SMEs should use a more extensive and more diverse sample of SMEs to provide possibilities for generalization of results. Future research could widen the range of individuals surveyed in the enterprise at the strategic level and the tactical and operational levels, if necessary. Different roles in the enterprise may reflect different perceptions and practices of ITG mechanisms. Moreover, a cross-national study could provide insights regarding cultural differences in adoption decisions and exploitation practices. Additionally, quantitative research could be applied to evaluate and generalize the findings of this research. Finally, future research should explore the relationship between ITG mechanisms and contingency factors and the impact on individual mechanisms.

However, implementing ITG is not easy as its definition and roles are not yet fully clarified. Therefore, determining the suitable ITG model and mechanisms remains a complex challenge. ITG must be an integral part of corporate governance and evolve in parallel to it. While there is no single right way for enterprises to address ITG improvements, it is necessary to continue research and handle all the questions regarding ITG mechanisms, such as which mechanisms affect ITG and how they are interconnected. Based on our research, we believe that by recognizing and incorporating contingency theory through ITG 
mechanisms, contingency factors, user needs and business objectives, significantly more appropriate and effective ITG models can be developed and implemented in place of the currently dominant models. Based on the problems in practice and the problems identified in the literature, and the result of our previous research, our final goal is to develop an adaptive strategic ITG model based on contingency theory to fill the gap in both practice and literature. This paper has set directions on one case study that will form the basis for further research.

Author Contributions: Conceptualization, A.L., A.P. and T.H.; methodology, A.L., A.P. and T.H.; validation, A.L., A.P. and T.H.; formal analysis, A.L.; investigation, A.L. and T.H.; resources, A.L. and T.H.; data curation, A.L.; writing-original draft preparation, A.L. and T.H.; writing-review and editing, A.L., A.P. and T.H.; visualization, A.L. All authors have read and agreed to the published version of the manuscript.

Funding: This research was supported by the Slovenian Research Agency; Program No. P5-0018Decision Support Systems in Digital Business.

Institutional Review Board Statement: Not applicable.

Informed Consent Statement: Informed consent was obtained from all subjects involved in the study.

Data Availability Statement: Not applicable.

Conflicts of Interest: The authors declare no conflict of interest.

\section{References}

1. Valentine, E.; de Haes, S.; Timbrell, G. The board's role in the governance of enterprise information and technology. In The Handbook of Board Governance: A Comprehensive Guide for Public, Private and Not-for-Profit Board Members; Leblanc, R., Ed.; Wiley Online Library: Hoboken, NJ, USA, 2016; pp. 574-596.

2. Turel, O.; Liu, P.; Bart, C. Board-level information technology governance effects on organizational performance: The roles of strategic alignment and authoritarian governance style. Inf. Syst. Manag. 2017, 34, 117-136. [CrossRef]

3. Rusu, L.; Gianluigi, V. Information Technology Governance in Public Organizations, 1st ed.; Springer: Cham, Switzerland, 2017.

4. de Haes, S.; Huygh, T.; Joshi, A. Exploring the contemporary state of information technology governance transparency in Belgian firms. Inf. Syst. Manag. 2017, 34, 20-37. [CrossRef]

5. Huygh, T.; de Haes, S. Exploring the research domain of IT governance in the SME context. Int. J. It/Bus. Alignment Gov. 2016, 7, 20-35. [CrossRef]

6. Lunardi, G.L.; Macada, A.C.G.; Becker, J.L.; van Grembergen, W. Antecedents of IT governance effectiveness: An empirical examination in Brazilian firms. J. Inf. Syst. 2017, 31, 41-57. [CrossRef]

7. Nolan, R.; McFarlan, F.W. Information technology and the board of directors. Harv. Bus. Rev. 2005, 83, 96.

8. Turel, O.; Bart, C. Board-level IT governance and organizational performance. Eur. J. Inf. Syst. 2014, 23, 223-239. [CrossRef]

9. Jewer, J.; Mckay, K.N. Antecedents and consequences of board IT governance: Institutional and strategic choice perspectives. J. Assoc. Inf. Syst. 2012, 13, 581-617. [CrossRef]

10. Hovelja, T. Organisational effects on Information Technology productivity in enterprises: The case of Slovenia. Econ. Bus. Rev. Cent. South-Eastern Eur. 2008, 10, 243.

11. Tiwana, A.; Konsynski, B.; Venkatraman, N. Special issue: Information technology and organizational governance: The IT governance cube. J. Manag. Inf. Syst. 2013, 30, 4-7. [CrossRef]

12. Selig, G.J. IT governance-An integrated framework and roadmap: How to plan, deploy and sustain for improved effectiveness. J. Int. Technol. Inf. Manag. 2016, 25, 55-77.

13. Pereira, R.; da Silva, M.M. Towards an Integrated IT Governance and IT Management Framework. In Proceedings of the 2012 IEEE 16th International Enterprise Distributed Object Computing Conference (EDOC), Beijing, China, 10-14 September 2012; pp. 191-200.

14. de Haes, S.; van Grembergen, W.; Debreceny, R.S. COBIT 5 and enterprise governance of information technology: Building blocks and research opportunities. J. Inf. Syst. 2013, 27, 307-324. [CrossRef]

15. Ridley, G.; Young, J.; Carroll, P. COBIT and its utilization: A framework from the literature. In Proceedings of the 37th Annual Hawaii International Conference on System Sciences, Big Island, HI, USA, 5-8 January 2004; pp. 1-8.

16. Kam, H.-J.; Katerattanakul, P.; Hong, S. It Governance Framework: One Size Fits All? In AMCIS 2016 Proceedings; No. Reis 1997; Association for Information Systems (AIS): San Diego, CA, USA, 2016; pp. 1-10.

17. Bianchi, I.S.; Sousa, R.; Pereira, R.; Haes, S. The Influence of Culture in IT Governance Implementation: A Higher Education Multi Case Study. Int. J. Hum. Cap. Inf. Technol. Prof. 2019, 10, 55-68. [CrossRef]

18. Asgarkhani, M.; Cater-Steel, A.; Toleman, M.; Ally, M. Failed IT projects: Is poor IT governance to blame? In Proceedings of the Australasian Conference on Information Systems, Hobart, Australia, 4-6 December 2017; pp. 1-9. 
19. Bianchi, I.S.; Sousa, R.D.; Pereira, R. IT governance Mechanisms at Universities: An Exploratory Study. In Proceedings of the Twenty-third Americas Conference on Information Systems, Boston, MA, USA, 10-12 August 2017; pp. 1-11.

20. Almeida, R.; Lourinho, R.; da Silva, M.M.; Pereira, R. A model for assessing COBIT 5 and ISO 27001 simultaneously. In Proceedings of the 2018 IEEE 20th Conference on Business Informatics (CBI), Vienna, Austria, 11-14 July 2018; pp. 60-69.

21. Radovanović, D.; Radojević, T.; Lučić, D.; Šarac, M. IT audit in accordance with Cobit standard. In Proceedings of the 33rd International Convention MIPRO, Opatija, Croatia, 24-28 May 2010; pp. 1137-1141.

22. Winniford, M.A.; Conger, S.; Erickson-Harris, L. Confusion in the ranks: IT service management practice and terminology. Inf. Syst. Manag. 2009, 26, 153-163. [CrossRef]

23. Debreceny, R.S.; Gray, G.L. IT governance and process maturity: A multinational field study. J. Inf. Syst. 2013, 27, 157-188. [CrossRef]

24. Kolar, A.; Groznik, A. Standards, best practices and codes of ethics impact on IT service quality-The case of Slovenian IT departments. Econ. Bus. Rev. 2017, 19, 51-72. [CrossRef]

25. Silva, D.; da Silva, M.M.; Pereira, R. Baseline mechanisms for enterprise governance of IT in SMEs. In Proceedings of the 2018 IEEE 20th Conference on Business Informatics (CBI), Vienna, Austria, 11-14 July 2008; Volume 2, pp. 32-41.

26. OECD. The Digital Transformation of SMEs; OECD Publishing: Paris, France, 2021.

27. Pucihar, A.; Lenart, G.; Marolt, M.; Maletič, D.; Borštnar, M.K. Business model innovation: Insights from a multiple case study of Slovenian SMEs. Organizacija 2016, 49, 161-171.

28. Bergeron, F.; Croteau, A. A Framework for Research on Information Technology Governance in SMEs. In Start-Ups and SMEs: Concepts, Methodologies, Tools, and Applications; Khosrow-Pour, M., Ed.; IGI Global: Hershey, PA, USA, 2020; pp. 1567-1588.

29. Bergeron, F.; Croteau, A.-M.; Uwizeyemungu, S.; Raymond, L. IT Governance Framework Applied to SMEs. Int. J. It/Bus. Alignment Gov. 2015, 6, 33-49. [CrossRef]

30. Devos, J.; van Landeghem, H.; Deschoolmeester, D. Rethinking IT governance for SMEs. Ind. Manag. Data Syst. 2012, 112, 206-223. [CrossRef]

31. Devos, J.; van Landeghem, H.; Deschoolmeester, D. IT governance in SMEs: Trust or control? In Information Systems—Creativity and Innovation in Small and Medium-Sized Enterprises; IFIP Advances in Information and Communication Technology; Springer: Berlin/Heidelberg, Germany, 2009; Volume 301, pp. 135-149.

32. Bergeron, F.; Croteau, A.M.; Uwizeyemungu, S.; Raymond, L. IT governance theories and the reality of SMEs: Bridging the gap. In Proceedings of the 2015 48th Hawaii International Conference on System Sciences, Kauai, HI, USA, 5-8 January 2015; pp. 4544-4553.

33. Huang, R.; Zmud, R.W.; Price, R.L. IT Governance Practices in Small and Medium-Sized Enterprises: Recommendations from an Empirical Study. Ifip Int. Fed. Inf. Process. 2009, 301, 158-179.

34. Thong, J.Y.L. An integrated model of information systems adoption in small businesses. J. Manag. Inf. Syst. 1999, 15, 187-214. [CrossRef]

35. Sambamurthy, V.; Zmud, R.W. Arrangements for information technology governance: A theory of multiple contingencies. MIS Q. 1999, 23, 261-290. [CrossRef]

36. Oehmichen, J.; Schrapp, S.; Wolff, M. Who needs experts most? B oard industry expertise and strategic change-A contingency perspective. Strateg. Manag. J. 2017, 38, 645-656. [CrossRef]

37. Müller, R.; Zhai, L.; Wang, A. Governance and governmentality in projects: Profiles and relationships with success. Int. J. Proj. Manag. 2017, 35, 378-392. [CrossRef]

38. Kast, F.E.; Rosenzweig, J.E. Contingency Views of Organization and Management; Science Research Associates: Chicago, IL, USA, 1973.

39. Weill, P.; Olson, M.H. An assessment of the contingency theory of management information systems. J. Manag. Inf. Syst. 1989, 6, 59-86. [CrossRef]

40. European Commission; Executive Agency for Small and Medium-sized Enterprises; Lonkeu, O.; Jessie, W.; Bormans, J.; Pedersen, B.; Mühlschlegel, T.; Braun, H.; Thomas, C.; Jonathan, S.; et al. Annual Report on European SMEs 2018/2019: Research E Development and Innovation by SMEs; Publications Office: Luxembourg, 2020. [CrossRef]

41. de Haes, S.; van Grembergen, W. An exploratory study into the design of an IT governance minimum baseline through Delphi research. Commun. Assoc. Inf. Syst. 2008, 22, 443-459. [CrossRef]

42. Webster, J.; Watson, R.T. Analyzing the past to prepare for the future: Writing a literature review. MIS Q. 2002, 26, xiii-xxiii.

43. Nakano, D.; Muniz, J., Jr. Writing the literature review for empirical papers. Production 2018, 28, xiii-xxiii. [CrossRef]

44. Fama, E.F.; Jensen, M.C. Separation of ownership and control. J. Law Econ. 1983, 26, 301-325. [CrossRef]

45. Kooper, M.N.; Maes, R.; Lindgreen, E.E.O.R. On the governance of information: Introducing a new concept of governance to support the management of information. Int. J. Inf. Manag. 2011, 31, 195-200. [CrossRef]

46. Spafford, G. The Benefits of Standard IT Governance Frameworks. Available online: https://www.datamation.com/networks / the-benefits-of-standard-it-governance-frameworks / (accessed on 21 June 2021).

47. de Haes, S.; van Grembergen, W. An exploratory study into IT governance implementations and its impact on business/IT alignment. Inf. Syst. Manag. 2009, 26, 123-137. [CrossRef]

48. Weill, P.; Ross, J.W. IT Governance: How Top Performers Manage IT Decisions Rights for Superior Results, 1st ed.; Harvard Business Press: Boston, MA, USA, 2004.

49. de Haes, S.; van Grembergen, W. IT governance and its mechanisms. Inf. Syst. Control J. 2004, 1, 1-14. 
50. Weill, P. Don't just lead, govern: How top-performing firms govern IT. MIS Q. Exec. 2004, 8, 1-21.

51. van Grembergen, W.; de Haes, S. Implementing Information Technology Governance; IGI Publisher: New York, NY, USA, 2008.

52. Pereira, R.; da Silva, M.M. A Literature Review: Guidelines and Contingency Factors for IT Governance. Eur. Mediterr. Middle East. Conf. Inf. Syst. 2012, 2012, 342-360.

53. Dahlberg, T.; Lahdelma, P. IT governance maturity and IT outsourcing degree: An exploratory study. In Proceedings of the Annual Hawaii International Conference on System Sciences, Big Island, HI, USA, 3-6 January 2007.

54. de Haes, S.; van Grembergen, W. Analysing the relationship between IT governance and business/IT alignment maturity. In Proceedings of the Annual Hawaii International Conference on System Sciences, Big Island, HI, USA, 7-10 January 2008.

55. Webb, P.; Pollard, C.; Ridley, G. Attempting to define IT governance: Wisdom or folly? In Proceedings of the 39th Annual Hawaii International Conference on System Sciences, Kauai, HI, USA, 4-7 January 2006; Volume 8.

56. van Grembergen, W.; de Haes, S.; Guldentops, E. Structures, Processes and Relational Mechanisms for It Governance; IGI Global: Hershey, PA, USA, 2004; pp. 1-36.

57. de Haes, S.; van Grembergen, W. Enterprise Governance of Information Technology: Achieving Strategic Alignment and Value; Springer: Berlin/Heidelberg, Germany, 2009.

58. IT Governance Institute. Board Briefing for IT Governance, 2nd ed.; ISACA: Rolling Meadows, IL, USA, 2003.

59. Broadbent, M. Understanding IT governance. CIO Can. 2003, 11, 4.

60. Lunardi, G.L.; Becker, J.L.; Maçada, A.C.G. The financial impact of IT governance mechanisms' adoption: An empirical analysis with Brazilian firms. In Proceedings of the 42nd Hawaii International Conference on System Sciences, Big Island, HI, USA, 5-8 January 2009; pp. 1-10.

61. Weill, P.; Ross, J.W. IT Governance on One Page; Massachusetts Institute of Technology: Cambridge, MA, USA, 2004.

62. Craig, S. IT Governance Framework—Best Practices; Forrester Research: Cambridge, MA, USA, 2005; pp. 1-17.

63. Luftman, J. Assessing business-IT alignment maturity. Commun. Assoc. Inf. Syst. 2000, 4, 14. [CrossRef]

64. Peterson, R. Integration strategies and tactics for information technology governance. In Strategies for Information Technology Governance; van Grembergen, W., Ed.; IGI Publishing: Hershey, PA, USA, 2004; pp. 37-81.

65. Spremić, M. IT governance mechanisms in managing IT business value. Corp. Gov. 2009, 6, 906-915.

66. Short, J.; Gerrard, M. IT Governance Must Be Driven by Corporate Governance; Gartner, Inc.: Stamford, CT, USA, 2009 ; pp. 1-7.

67. van Grembergen, W.; de Haes, S.; Thorp, J. Implementing Information Technology Governance: Models, Practices and Cases; IGI Publisher: Hershey, PA, USA, 2007.

68. Herz, T.; Hamel, F.; Uebernickel, F.; Brenner, W. IT governance mechanisms in multisourcing-A business group perspective. In Proceedings of the 2012 45th Hawaii International Conference on System Sciences, Maui, HI, USA, 4-7 January 2012; pp. 5033-5042.

69. Symons, C. IT Strategy Maps: A Tool for Strategic Alignment; Forrester Research Inc.: Cambridge, UK, 2005.

70. Weill, P.; Ross, J.W. A matrixed approach to designing IT governance. MIT Sloan Manag. Rev. 2005, 46, 26-34.

71. Jacobson, D.D. Revisiting IT governance in the light of institutional theory. In Proceedings of the 42nd Annual Hawaii International Conference on System Sciences, HICSS, Waikoloa, HI, USA, 5-8 January 2009.

72. Broadbent, M. CIO futures-Lead with effective governance. In Proceedings of the ICA 36th Conference, Singapore, 22-24 October 2002; pp. 1-11.

73. Maidin, S.S.; Arshad, N.H. IT governance practices model in IT project approval and implementation in Malaysian public sector. In Proceedings of the ICEIE 2010-2010 International Conference on Electronics and Information Engineering, Kyoto, Japan, 1-3 August 2010; Volume 1.

74. Gerrard, M. Defining IT governance: The Gartner IT governance demand/supply model; Gartner, Inc.: Stamford, CT, USA, 2010; pp. 1-8.

75. Simonsson, M.; Johnson, P. Defining IT governance-A consolidation of literature. In Proceedings of the 18th Conference on Advanced Information Systems Engineering, Luxembourg, 5-9 June 2006; Volume 6, pp. 1-19.

76. Delone, W.; Migliorati, D.; Vaia, G. Digital IT governance. In CIOs and the Digital Transformation; Springer International Publishing: Cham, Switzerland, 2018; pp. 205-230.

77. Ross, J.; Sebastian, I.; Beath, C.; Scantlebury, S.; Mocker, M.; Fonstad, N.; Kagan, M.; Moloney, K. Designing Digital Organizations; Massachusetts Institute of Technology: Cambridge, MA, USA, 2016.

78. Silva, E.; Chaix, Y. Business and IT governance alignment simulation essay on a business process and IT service model. In Proceedings of the Annual Hawaii International Conference on System Sciences, Big Island, HI, USA, 7-10 January 2008.

79. Simonsson, M.; Johnson, P. The IT organization modeling and assessment tool: Correlating IT governance maturity with the effect of IT. In Proceedings of the 41st Annual Hawaii International Conference on System Sciences, Waikoloa, HI, USA, 7-10 January 2008.

80. Dahlberg, T.; Kivijärvi, H. An integrated framework for IT governance and the development and validation of an assessment instrument. In Proceedings of the 39th Hawaii International Conference on System Sciences, Kauai, HI, USA, 4-7 January 2006; pp. 1-10.

81. Shpilberg, D.; Berez, S.; Puryear, R.; Shah, S. Avoiding the alignment trap in information technology. MIT Sloan Manag. Rev. 2007, $49,51-58$

82. Montazemi, A.R.; Pittaway, J.J. Getting Them to Think Outside the Circle: Corporate Governance, CEOs' External Advice Networks, and Firm Performance; Academy of Management: Briarcliff Manor, NY, USA, 2012; Volume 51. 
83. Hevner, A.R.; March, S.T.; Park, J.; Ram, S. Design Science in Information Systems research. Des. Sci. IS Res. MIS Q. 2004, 28, 75-105. [CrossRef]

84. Gable, G.G. Integrating case study and survey research methods: An example in information systems. Eur. J. Inf. Syst. 1994, 3, 112-126. [CrossRef]

85. Eisenhardt, K.M. Building theories from case study research. Acad. Manag. Rev. 1989, 14, 532-550. [CrossRef]

86. Gerring, J. What is a case study and what is it good for? Am. Polit. Sci. Rev. 2004, 98, 341-354. [CrossRef]

87. Das, R.K.; Singha, A. Case study as a research method. Glob. Res. Methodol. J. 2011, 3, 1-6.

88. Noor, K.B.M. Case study: A strategic research methodology. Am. J. Appl. Sci. 2008, 5, 1602-1604. [CrossRef]

89. Rowley, J. Using case studies in research. Manag. Res. News 2002, 25, 16-27. [CrossRef]

90. Yin, R.K. Case Study Research and Applications, Design and Methods, 6th ed.; SAGE Publications: Los Angeles, CA, USA; London, UK; New Delhi, India; Singapore; Washington, DC, USA; Melbourne, Australia, 2011.

91. Thomas, G. How to Do Your Research Project: A Guide for Students, 3rd ed.; Sage: London, UK, 2017.

92. Grady, M.P. Qualitative and Action Research: A Practitioner Handbook; Phi Delta Kappa International: Arlington, VA, USA, 1998.

93. Mason, M. Sample size and saturation in PhD studies using qualitative interviews. Forum Qualitative Sozialforschung/Forum Qual. Soc. Res. 2010, 11. [CrossRef]

94. Baker, S.E.; Edwards, R.; Doidge, M. How Many Qualitative Interviews Is Enough?: Expert Voices and Early Career Reflections on Sampling and Cases in Qualitative Research; National Centre for Research Methods: Southampton, UK, 2012.

95. de Haes, S.; van Grembergen, W. Practices in IT governance and business/IT alignment. Inf. Syst. Control J. 2008, 2, 1-6.

96. Almeida, R.; Pereira, R.; Mira da Silva, M. IT Governance Mechanisms: A Literature Review. In Exploring Services Science; Falcão e Cunha, J., Snene, M., Nóvoa, H., Eds.; IESS 2013. Lecture Notes in Business Information Processing; Springer: Berlin/Heidelberg, Germany, 2013; Volume 143. [CrossRef]

97. Almeida, R.; Pereira, R.; da Silva, M.M. IT governance mechanisms patterns. In Proceedings of the Advanced Information Systems Engineering Workshops, Valencia, Spain, 17-21 June 2013; Volume 148, pp. 156-161.

98. Wu, S.P.-J.; Straub, D.W.; Liang, T.-P. How Information Technology Governance Mechanisms and Strategic Alignment Influence Organizational Performance: Insights from a Matched Survey of Business and IT Managers. Manag. Inf. Syst. Q. 2015, 39, 497-518. [CrossRef]

99. Opitz, N.; Krüp, H.; Kolbe, L.M. How to Govern your Green IT?-Validating a Contingency Theory Based Governance Model. PACIS 2014 Proceedings. Pacific Asia Conference on Information Systems: Virtual Conference. 2014. Available online: https: / / aisel.aisnet.org/pacis2014/333 (accessed on 21 June 2021).

100. Bartenschlager, J.; Goeken, M. Designing artifacts of IT strategy for achieving business/IT alignment. In AMCIS 2009 Proceedings; Association for Information Systems (AIS): San Francisco, CA, USA, 2009; p. 494.

101. Rowlands, B.; de Haes, S.; van Grembergen, W. Exploring and Developing an IT Governance Culture Framework. In Proceedings of the International Conference on Information Systems, Auckland, New Zealand, 14-17 December 2014; pp. 1-9.

102. Bianchi, I.S.; Pereira, R.; Sousa, R.; Hillegersberg, J. Baseline Mechanisms for IT Governance at Universities. In Proceedings of the European Conference on Information Systems (ECIS) 2017, Guimarães, Portugal, 5-10 June 2017; pp. 1551-1567.

103. Pereira, R.; Almeida, R.; da Silva, M.M. IT governance patterns in the portuguese financial industry. In Proceedings of the 2014 47th Hawaii International Conference on System Sciences, Waikoloa, HI, USA, 6-9 January 2014; pp. 4386-4395.

104. Levstek, A.; Hovelja, T.; Pucihar, A. IT governance mechanisms and contingency factors: Towards an adaptive IT governance model. Organizacija 2018, 51, 286-310. [CrossRef]

105. IT Governance Institute. COBIT 5; ISACA, IT Governance Institute: Rolling Meadows, IL, USA, 2012. 